\title{
Analyzing the Legal Dimensions of Unmanned Combat Aerial Vehicle in the International Law
}

\author{
Reza Mousazadeh ${ }^{1}$, Abbas Basiri ${ }^{2}$, Mojtaba Babaee $^{2} \&$ Ali Tavakoli Tabasi ${ }^{2}$ \\ ${ }^{1}$ International Relations School, Iran \\ ${ }^{2}$ Payame Noor University, Tehran, Iran \\ Correspondence: Abbas Basiri, Payame Noor University, P. O. Box 19395-3697, Tehran, Iran. E-mail: \\ abbasbasiri222@gmail.com
}

Received: May 23, 2016 Accepted: June 18, 2016 Online Published: November 30, 2016

doi:10.5539/jpl.v9n10p1 URL: http://dx.doi.org/10.5539/jpl.v9n10p1

\begin{abstract}
The concept of manufacturing unmanned aircrafts developed before the Second World War. However after World War II, the use of these aircrafts in aerial identification missions increased. In the recent decade, unmanned combat aerial vehicles used in order to identify and attack enemies in a direct manner. Unlike Classic wars, the future armed conflicts will focus on the use of military robots that have the ability to fight with robotic armaments which are 1000 kilometers distant from the battlefield and controlled by a person or function in an independent manner. According to the article 36 of the first protocol, each country should be informed about the legal principles of using different forms of robotic armaments such as unmanned combat aerial vehicles. In other words, no specific article or provision has been defined in the international law regarding the inhibition or restriction of manufacturing and developing these armaments. Although according to weapons law, these armaments don't violate the principle of international law and they don't threat human right. As a result any use of these unmanned combat aerial vehicles is not illegal. However, it is unlikely that using advanced remote/ robotic armaments be legal or don't violate the principles of humanitarian law.
\end{abstract}

Keywords: legitimacy, international law, humanitarian law, unmanned combat aerial vehicle

\section{Introduction}

After World War II, the use of unmanned aircrafts in aerial identification missions increased (Konstantions, 2012:16). However, the development of new generation of these aircrafts equipped with modern systems began in the second half of the $20^{\text {th }}$ century. These aircrafts could not only be used in aerial identification missions but also they had the ability to attack the enemies or other targets in a direct manner. In the recent decade, unmanned combat aerial vehicles have developed (Melzer, 2013:7). More than 50 countries have manufactured and developed more than 1000 unmanned aircrafts (Op.cit.Konstantinos:24-26). The process of manufacturing these aircrafts is increasing in a rapid manner. Even non-governmental or private sectors use and benefit from this technology (Quintana, 2008:11). An unmanned combat aerial vehicle consists of an advanced remote/robotic armament system equipped with electronic sensors and munitions of war. These systems used in identification missions in order to identify war and military zones and monitor the battlefield. Also, they have the power to detect other manned combat aerial vehicles and target them in a direct manner (http://www.britannica.com/technology/military-aircraft/Unmanned-aerial-vehicles-UAVs).

Unlike classic wars, the future armed conflicts will remarkably rely on military robots that have the power to identify and attack robotic armaments controlled by an operator that is thousands of kilometers away from the battlefield or it can function in an independent manner. The new generation of these armaments can only indicate the top of the ice mountain. These developing armaments can gradually limit the function of operator or eliminate it. Therefore, the structure and form of wars will be changed which can result in the formation of legal challenges and issues (Leveringhaus, 2014:7).

Now, the question is that is it possible to consider unmanned combat aerial vehicles as war armaments or new tactics of war also can we analyze the legitimacy of these armaments based on article 36 of the first protocol which was defined in 1977 and in The Geneva Conventions consisted of four treaties? If we suppose that the answer is positive, how can we analyze the legitimacy of using unmanned combat aerial vehicles based on the principles of the international law? 
This research aims at finding the best answers to these questions and analyzing them based on two different discourses. According to the first discourse, the legitimacy of unmanned combat aerial vehicles can be identified based on the provisions and principles of the international law. The other discourse focuses on the application of unmanned aircrafts based on the armed conflict law.

\subsection{First Discourse: The Legitimacy of Unmanned Combat Aerial Vehicles in the International Law}

In this discourse, the legitimacy of unmanned combat aerial vehicles has been analyzed regardless of their application in the provisional and conventional international law.

1.1.1 First Clause: The Prohibition or Limitation of Using Unmanned Combat Aerial Vehicle Based on the Principles of the Provisional International Law

According to the principle of the provisional international law, the parties to the conflict can use different war tactics and armaments and only unnecessary weapons that can have destructive effects have been prohibited (Article 35 of the first protocol (1977)). As a result, when governments decide to test or develop these armaments or train soldiers in order to use a weapon, armament, or new war tactic, they should be informed about the legitimacy of using these armaments based on the first protocol or other principles of the international law (Article 36 of the first protocol (1977)). Therefore, they are obliged to analyze the legitimacy of new armaments not only based on the principles of international humanitarian law but also the principles of the international law in order to inhibit different countries from manufacturing and developing armaments, war equipment, and tactics that violate the international law. However, before analyzing the legitimacy of these armaments, the most important thing is identifying the correctness/incorrectness of the fact that unmanned combat aerial vehicle is considered as an armament or war equipment. According to the interpretation of the International Committee of the Red Cross in article 36 of the first protocol regarding different forms of armaments, war equipment, and tactics, unmanned combat aerial vehicles can be considered as armaments (ICRC, 2006: 936-937). Also considering the strategy of analyzing the legitimacy of different armaments, war equipment, and tactics developed in 2006, the international committee of the Red Cross has declared that, all the war equipment and tactics can be used in wars. This committee also referred to the weapons law and documents of Australia that emphasized on the destructive and threatening effects of armaments as offensive and defensive weapons. According to these documents, armament systems, munitions of war, and targeting systems can have destructive effects (Yan, 2012:635). Considering the interpretation of the international committee of the Red Cross, unmanned combat aerial vehicles can be considered as armaments. As a result, Article 36 of the first protocol can be attributed to different forms of armaments from antipersonnel and anti-equipment, lethal and non-lethal weapons to armament systems (Op.cit.Lawand:9). Therefore, it is necessary to analyze the legitimacy of unmanned combat aerial vehicles based the Article 36 of the first protocol.

The first Convention that has analyzed the legitimacy of these armaments is known as Chicago Convention. This convention has limited the use of unmanned combat aerial vehicles in some cases. However, no limitation is defined regarding the development or manufacturing of these armaments. Also article to the article 3 of this convention, this principle cannot be attributed to unmanned combat aerial vehicles.

The missile technology control regime can be considered as a voluntary and informal coalition among 34 countries in an international level that inhibits different states from developing and manufacturing missile technology and unmanned combat aerial vehicles which developed in 1987 and have the ability to carry $500 \mathrm{~kg}$ warhead for at least $300 \mathrm{~km}$ (Loewen, 2013:2). The missile technology control consists of Ballistic missiles, spatial launchers, and unmanned vehicles such as Cruise missile and unmanned aerial vehicles (UAVs) (http://Fas.org/nuke/control/mtcr). The initial objective of the missile technology control regime is controlling the transportation of war equipment and technologies efficient in unmanned combat aerial systems. The members of this regime have been obliged to avoid transporting the war products mentioned in the appendix part of the agreement to other states unless the target countries guarantee that they will never use these products in the process of manufacturing unmanned combat aerial vehicles (Saed, 2007: 47). In fact, this regime aims at inhibiting countries from developing unmanned combat aerial systems. However, it has no legal power or right to take legal actions and the powers of the members is limited to their national capacities (McDogal, 2003:24). In other words, the missile technology control regime can't guarantee that if a country violates these principles, it can take legal actions. As a result these states have politically undertaken to accept the decisions of the domestic legal systems in order to take legal actions consistent with the policies for controlling unmanned combat aerial system technology (Saed, 2007:50). One of the disadvantages of the missile technology control regime is that it avoids horizontal expansion or in other words development of countries that use unmanned combat aerial systems. This regime never inhibits its members from vertical expansion but obliged them to avoid transporting 
unmanned combat aerial systems' equipment to developing countries (Ibid: 53). The treaty on conventional armed forces in Europe was formed in 1990. This convention aims at restricting the development of some of the armaments such as combat aerial vehicles. Russia and member states of NATO signed this convention (Collina, 2012:1). In 1992-2008, the members of this treaty obliged to limit the development of 52000 armaments (Ibid: 2).In 2007, Russia refused to sign this convention (Mirfakhraei, H. 2007, 127). According to the Article 1 of the protocol, all the parties to the treaty obliged to decrease and limit the process of manufacturing military weapons and equipment such as combat aerial vehicles. Also considering the Article 4 of this convention, every state is obliged to reduce the number of its combat aerial vehicles 40 months later (After taking legal actions regarding this convention). According to the clause $\mathrm{k}$ of article 2, combat aerial vehicle can be defined as a fixed wing aircraft equipped with guided and unguided missiles, bombs, and other destructive armaments include different kinds of combat aerial vehicles that can be used in electronic warfare and identification missions. In 2008, the treaty on conventional armed forces in Europe was suspended due to Russia's reaction toward signing the convention in 2007 (Lachowski, 2009). The definition of "combat aerial vehicle" mentioned in this treaty can be attributed to unmanned combat aerial vehicles. Therefore, no specific convention is defined in the international law regarding the prohibition or restriction of developing and manufacturing unmanned combat aerial vehicles.

1.1.2 Second Clause: The Prohibition or Restriction of Developing and Manufacturing Unmanned Combat Aerial Vehicles Based on the Principles of the Conventional International Law

According to the second clause, all the states obliged to analyze the legitimacy of using different forms of armaments in battlefield based on the principles of the international law and conventional international law (Article 36 of the first protocol). The features, applications, and predictable effects of new armaments can somehow help these states to analyze the legitimacy of them. For instance, if the destruction radius of an armament increases, the use of it against one or multiple military targets which should be identified among civilians becomes difficult especially when these states obliged to avoid using war tactics and equipment in battlefields. Therefore it is necessary to consider all the issues from legal principles to different applications of these armaments in battlefields and issue the usage license (Op.cit.Lawand:15). As a result, the conventional international law can be considered as one of the important mechanisms that analyzes the prohibition or restriction of using new armaments. In order to identify the legitimacy of a new armament such as unmanned combat aerial vehicle based on the principles of the conventional international law, the states can analyze their function regarding the principles of humanitarian law based on both weapons law and targeting law. In weapons law, the armament system or unmanned combat aerial vehicle will be analyzed in order to identify the legitimacy of it. First it is important to analyze the destructive effects of armament systems and then their ability in identifying military targets among civilians. On the other hand, targeting law which will be explained later refers to the process of analyzing the use of armament systems in battlefields and identifying their legitimacy based on the principles of the humanitarian law (Thomas, 2015:246-247). According to the first principle (weapons law), it is necessary to analyze the legitimacy of armament systems based on the two fundamental components: The principle of prohibiting superfluous injury and unnecessary suffering and the principle of discrimination.

\subsection{The Principle of Prohibiting Superfluous Injury and Unnecessary Suffering}

The use of armaments and war tactics that may have superfluous injury and unnecessary suffering is prohibited. This principle which is considered as a conventional international law can be used in both international and non-international armed conflicts (Henckartz, 2008:364).

There is no doubt that the destructive and harmful effects of these armaments are inevitable. This principle only considers unnecessary effects and analyzes them based on two dimensions: qualitative \& quantitative dimensions. The qualitative dimension analyzes the role of different war tactics in increasing these destructive and harmful effects. This information is not always available. For instance, countries may don't have access to this information during the process of manufacturing armaments. However, it is necessary to consider the potential effects of these systems on individuals during war. In other words, these studies can reduce the destructive effects of war. On the other hand, the quantitative dimension focuses on the rate and range of these effects. It means that it estimates the number of victims of war killed or injured by these armaments. The quantitative dimension is somehow related to the principle of distinguishing military targets from civilians. In the process of analyzing the legitimacy of different armaments, all the principles regarding the use of war equipment should be considered. In general, all the armaments can have unnecessary destructive effects but the question is that can they have unnecessary destructive effects when they are used for non-military purposes? (Mcclelland, 2003:407). Despite of the acceptance of this conventional principle, different states have different ideas about the way of identifying the destructive and harmful effects of these armaments. They believe that any destructive effect of these armaments in non-military actions violate the conventional principle. Most states think that it is necessary 
to make a balance between military actions and additional harms. As a result, any harm that is not consistent with the expected military objectives violates this principle. In weapons law, unnecessary destructive effects and harms defined as "any harm that has inevitable effects and aims at reaching legal military objectives (Op.cit.Henckartz: 368-369). Now the question is that is it acceptable to consider unmanned combat aerial vehicles as armaments that can naturally have unnecessary destructive and harmful effects? Two approaches have been formed regarding the legitimacy of using unmanned combat aerial vehicles. According to one these approaches, unmanned combat aerial vehicles can't have unnecessary destructive and harmful effects and they aim at increasing individuals' security and military productivity also decreasing the destructive effects of war (Op.cit.Thomas:252-253). Therefore, it is not enough to consider these armaments illegal only because the can naturally have destructive effects (Ibid: 253). However, the other approach emphasizes on the process of analyzing the function and power of unmanned combat aerial vehicles before and during attacks. However, this process in itself may have unnecessary destructive effects. For example, these unmanned combat aerial vehicles don't give any chance to the military targets to be surrendered. They don't have the power to only identify the targets and then take them as prisoners of war (Fatima, 2014:377). For instance, if a combatant decides to be surrendered and hold his hands up or hold a white flag in his hands (The symbol of peace) in order to cease the fire, the unmanned combat aerial vehicle shouldn't attack him but the problem is that these armaments don't have this power and as a result they may kill or hurt the combatants (Mark, 2012:84). Also the aerial attacks of unmanned combat aerial vehicles are not predictable and they can put civilians and innocent people under mental and psychological pressures. All the mentioned issues violate the principle of humanitarian law and increase unnecessary destructive effects for combatants and civilians (Op.cit.Fatima:377).it seems that the first approach which has emphasized on the importance of analyzing the legitimacy of using unmanned combat aerial vehicles is consistent with weapons law and it is not possible to inhibit states from using these armaments based on the principle of prohibiting unnecessary destructive \& harmful effects. The second approach is consistent with targeting law which focuses on the application of unmanned combat aerial vehicles in wars. Considering this possible, it is possible to prohibit or restrict the development of these armaments.

\subsection{The Principle of Discrimination}

The international humanitarian law has prohibited use of weapons that don't have the power of discrimination. According to the Article 71 of the first protocol, it is illegal to use unmanned combat aerial vehicles that can't distinguish military targets from civilians. This principle also mentioned and emphasized in the charter of the international criminal court (Op.cit.Henckartz: 374-375) and the charter of the United Nations. According to the principles of the international court of justice, this form of prohibition is one of the fundamental principles of the international humanitarian law (Ibid, 376-377). A weapon that doesn't have the power of discrimination can be defined as a weapon that can't distinguish military targets from civilians and attack or hurt all the individuals (Ibid: 378-379). According to the article 519 (clause 4 B) of the first protocol of the Geneva Convention which consisted of four treaties, the military forces can only use armaments that have the power to distinguish military targets from civilians in a precise manner (Op.cit.Thomas:255). Also according to the clause $4 \mathrm{C}$ of the mentioned article, parties to the conflict can't use armaments that can have unpredictable effects (Ibid). In fact the Article 51 of the first protocol has analyzed the legitimacy of armament systems based on two approaches: 1Do they have the power of discrimination? 2- Is it possible to reduce the destructive effects of these armaments? Therefore, the legitimacy of all armaments should be analyzed based on these approaches. Now the question is that do they violate the principle of discrimination and its related approaches or not? The unmanned combat aerial vehicle in itself can't violate this principle. These armaments typically fly at a relatively low speed and can identify targets. The armaments' operator identifies the condition of the targets by using sensors, camera, and laser and finally launches the bombs toward them. It minimizes the risk of non-discrimination attacks (Wuschka, 2011:895-896). It is not possible to classify unmanned combat aerial vehicles as non-discrimination armaments (Alberstadt,2014:224) because they have been equipped with advanced remote armament systems (Op.cit.Wuschka:897). Also considering the weapons law, they are inherently legal (Hattan, 2015:1049) and none of the mentioned principles regarding the illegality of an armament system considered it illegal due to its independency. However considering the opponent approaches, independent unmanned combat aerial vehicles don't have the power of discrimination. Therefore it is not possible to control their destructive effects (Anderson, 2014:401). Most of the theories about the inability of independent unmanned combat aerial vehicles in distinguishing military targets from civilians can be analyzed based on theories about the aircrafts' technical matters (Foy, 2014:57-58). Also most of these approaches violate the principles of the humanitarian law because they have analyzed the legitimacy of using these armaments based on two different principles: "Weapons law" and "Targeting law". The former emphasizes on the legitimacy of unmanned combat aerial vehicles, the latter on the application of these armaments in battlefields. However, this form of illegality has been defined differently in 
these approaches. The weapons law can be attributed to armaments but the targeting law focuses on war tactics and techniques (Op.cit.Thomas:247). It is possible for an unmanned combat aerial vehicle to be legal in weapons law and illegal in targeting law. Also some of the legal principles emphasize on the use of these armaments on specific conditions (Op.cit.Anderson:401). As a result, the illegality aspect of using unmanned combat aerial vehicles in battlefields or on specific conditions (Targeting law) doesn't refer to the unlawful nature of them.

1.3.1 Second Discourse: The Legitimacy of Using Unmanned Combat Aerial Vehicles Based on the International Humanitarian Law

This discourse has analyzed the legitimacy of using unmanned combat aerial vehicles based on the international humanitarian law. The legitimacy of these armaments depends on their consistency with the principles of the international humanitarian law (Radziejowska, 2014:3). Therefore it can be concluded that this discourse analyzes the legitimacy of unmanned combat aerial vehicles based on the principles of the international humanitarian law, power of discrimination, compatibility ability, precautionary, and Martens clause.

\subsection{The Principle of Distinction}

The parties to the conflict should always distinguish civilians from combatants. All the attacks should only target combatants and they are not allowed to harm the civilians. All the states obliged to follow the principles of the international law in both international and non-international armed conflicts (Op.cit.Henckaerts: 62). The principle of discrimination has been defined in the Article 48 of the first protocol of the Geneva convention consisted of four treaties. According to this article, All the parties to the conflict should discriminate military targets and don't harm the civilians and their possessions. Also, the second clause of the Article 51 and 52 of this protocol emphasizes on the principle of discrimination. According to the statements of the international court of justice regarding the matter of nuclear weapons, this principle can be considered as one of the bases of the international humanitarian law and international law (Ibid:64-65). The United States and England have used these armaments in Afghanistan, Pakistan, Yemen, and Somalia for several times in order to fight against terrorism. Most of the time, these unmanned combat aerial vehicles targeted and killed civilians out of their houses, in bazar, or other places (Op.cit.Fatima:373). Now the question is that can advanced remote/robotic armament systems distinguish combatants from civilians in battlefields or out of them?

An unmanned combat aerial vehicle can be considered as a vehicle that consists of a combination of different complex technologies with numerous numbers of technical limitations which can result in non-discrimination of military targets from civilians. They have the power to harm the innocent people. It consists of complex sensors that help the operator to control and monitor the targets for a long period of time (Weizmann, 2013:35). However, the height and long-term monitoring can inhibit the sensors from distinguishing military targets from civilians in a precise manner. As a result they have encountered with serious challenges of the international humanitarian law. Also the limitation of gathering data and the quality of the information gathered by sensors of unmanned combat aerial vehicles can decrease the power of discrimination and as result the armaments may attack civilians (Ibid:39) and affects the power of discrimination regarding the distance between the aircrafts' operator and the military targets. The operator may simply identify a number of individuals in one area but can't discriminate armed one from civilians or wounded individuals or those who decided to cease the fire (Phil, 2013:25). According to the other features of unmanned combat aerial vehicles, these armaments don't have the power of discrimination. For example, a delay for about 1-4 seconds in the process of transferring data between the operator and the unmanned combat aerial vehicle can result in inevitable destructive effects for the civilians. Therefore they may be killed or attack by these armaments (Ibid: 26). The independent unmanned combat aerial vehicle violates the principle of discrimination because: first, it doesn't have the sensors or process system that plays an important role in distinguishing combatants from non-combatants especially in domestic wars and the process of identifying surrendering combatants and war wounded individuals. An independent unmanned combat aerial vehicle consists of a combination of different sensors including cameras, infrared, laser, and temperature sensors and radars. These sensors have the power to identify human but they can't give us any more information. Second, a computer can analyze all the data which is written in form of programming language but considering the principle of discrimination, the most important thing is that no specific principle is defined regarding the illegality of these armaments to be written in form of programming language and analyzed in a computer. Also the principles of weapons law are not in form of programming language. Third, if we suppose that these armaments use an identification mechanism in order to differentiate civilians from combatants, they still don't have enough information about the battlefield and as a result violate the principle of discrimination. Therefore, we can't rely on the principle of discrimination in order to analyze the legitimacy of using unmanned combat aerial vehicles (Sharkey, 2012:788-789). David Akerson, one of the teachers in the University of Denver, believes that independent armament systems violate the principle of the international humanitarian law because 
they don't have the power to follow its rule. One of the main disadvantages of using these armaments is that they can't discriminate military targets from civilians (Op.cit.Hattan:104). Armin Krishnan, a researcher in the field of military robots and assistant professor in the University of East Carolina has analyzed the three basic principles regarding the inability of advanced remote/robotic armament systems in discriminating military targets from civilians:

1) Lack of efficient identification systems in advanced remote/robotic armaments: The discrimination of military targets from civilians requires efficient information. Sensors can gather these data but not in a precise manner and these technologies can't distinguish human from non-human yet or in other words they don't have discrimination system.

2) Lack of compatibility of robotic armament systems with battlefields: These armaments have fundamental problems with the modern and complex condition of battlefields and can't receive appropriate information about them. This problem in itself makes it difficult for unmanned combat aerial vehicles to discriminate military targets from civilians.

3) Lack of efficient software: The sensor technology is not efficient and can't the information about war in an efficient and precise manner. Also they don't have the power of discrimination (Op.cit.Foy:57-59). For instance, Harpy is one of Israel's unmanned combat aerial vehicles that can attack and destroy the enemies' radars. This independent armament can discriminate enemies' radars from other radars although it violates the principle of discrimination. For example, it can't identify that the radar exists on an anti-aircraft station or on the roof of a school (Op.cit.Sharkey:788). As a result, it doesn't seem that unmanned combat aerial vehicles especially independent ones can discriminate combatants from civilians in battlefields and in modern battles that use civilians as human shields.

\subsection{The Principle of Proportionality}

"Any form of attack that can harm civilians or their possessions even when direct and identical military control is expected is illegal (Op.cit.Henckartz: 121). The principle of proportionality has been defined in the fifth clause of the Article 51 of the first protocol. Also, Article 57 of this protocol has emphasized on this principle. The principle of proportionality always considers these two basic components: 1- The possible destructive effects of these armaments for civilians and their possessions, 2- The advantages of the possible military attacks. If the possible destructive effects are more than the military advantages, the parties to the conflict are not permitted to attack. Both the principles of discrimination and proportionality can be defined differently in the field of humanitarian law though they are related to each other. In other words, if a robotic armament system doesn't have the power of discrimination, it can't follow the principles of compatibility (Op.cit.Foy:56). David Kilcullen, an expert on wars and the anti-rebel adviser of David Petraeus in 2009 has presented statistical data based on Pakistan news agency regarding the use of unmanned combat aerial vehicles in U.S.A. According to these data, when an armament is trying to attack a combatant it has the power to attack and kill 50 civilians. According to the reports of Daniel Bayman, in every armament's attack only one combatant and more than 10 civilians are killed. Professor Ocanal, one of the teachers in the university of Notre Dame has presented another statistical data. According to these data, these armaments can kill 50 civilians for one combatant. As a result they violate the principle of proportionality (Akerson, 2013:5). David Kilcullen also believes that it is necessary for the states to stop this form of aerial attacks. Because 700 Pakistani civilians killed for only 16 members of Al-Qaeda in 2006 as a result of unmanned combat aerial vehicles' attacks (Taghizadeh, 2012:72). The challenges regarding the ability of these independent armaments in following the principle of compatibility have increased. Therefore, it is necessary for the armaments to be compatible with different phases of compatibility principle. These armaments not only don't have the power of discrimination but also they are not compatible with war tactics and principles (Wagner, 2014:28). The various and complex nature of the principle of compatibility makes it impossible for the states to manufacture and develop remote/robotic armament systems to be used in battlefields. It is unlikely that the states find an efficient way to manufacture remote/ robotic aerial armaments that can not only discriminate military targets but also get consistent with different tactics and principles. The Human Rights Watch has also emphasized on the impossibility of using an efficient mental and psychological process in order to identify the degree of compatibility in independent armament systems (Expert Meeting of ICRC, 2014:83). Professor Noel Sharki, an expert on artificial intelligence and robotics believes that unlike men, independent armament systems can't make efficient decisions on certain conditions (Op.cit.phil:34).

\subsection{The Principle of Military Necessity}

The principle of military necessity plays an important role in the international humanitarian law that prohibits the use of these armaments due to having destructive and harmful effects (Ohlin, 2013: 1299). According to this 
principle it is possible to use force whenever it is necessary. This principle can be considered as a fundamental part of the international law (Herman, 2013:54). As a result, it is illegal to use force for any non-military purposes or when it is unnecessary. Also they are not legal due to having destructive and harmful effects (Op.cit.Thomas:265). The principle of military necessity has been defined in the second clause of the Article 52 of the first protocol. According to this principle, the attacks should be consistent with the military objectives and they shouldn't target civilians' possessions. In other words, they can only target things that can have positive or destructive effects on the military acts. The Article 8 of the international court of justice (1998) also emphasized on the deliberate killing of civilians, harming or attacking them, destroying or sacking their properties as war crimes that violate the principle of military necessity. Now the question is that are the unmanned combat aerial vehicles consistent with the principle of military necessity?

Using unmanned combat aerial vehicles that can have destructive and harmful effects and are not consistent with military objectives is illegal. Some experts believe that it is necessary to analyze the necessity of using unmanned combat aerial vehicles in wars (Vogel, 2011:16). According to the principle of military necessity, it is legal to use these armaments only to threat the enemies but not in form of a potential threat that may have negative consequences in the future. Also considering this principle, it is unlawful to use unmanned combat aerial vehicles in order to attack non-military targets because it can be considered as a potential threat for them (Op.cit.Melzer:31-32). As a result, it seems that United States' attacks which aimed at fighting against the terrorist in Pakistan and Yemen violates the principle of necessity. According to the results of the conference of the international committee of the Red Cross it is unlikely that these states become able to design an independent programming system for these armaments. Therefore, they have doubts about the capability of independent armament systems in following the principles of the international humanitarian law. These systems that somehow violate the mentioned principle can have destructive and harmful effects for men. (https://www.icrc.org/en/document/autonomous-weapon-systems-challenge-human-control-over-use-force). In 2012, the Human Rights Watch announced that, the principle of military necessity is similar to the principle of compatibility and therefore needs to be analyzed in an empirical manner. As a result, military forces can control their activities and use war tactics that are consistent with these principles. It is unlikely that these armament systems fulfill the principle of military necessity in an efficient manner. Applying this principle to independent armament systems may have inevitable destructive effects that restrict the use of them in battlefields and for military purposes (Docherty, 2012:34-35).

\subsection{The Principle of Precaution}

It is necessary to distinguish military forces from civilians and their properties in a precise manner. All these predictable precautionary measures aim at minimizing the degree of destructive and harmful effects of these attacks. Different states believe that it is possible to apply this principle to both international and non-international armed conflicts because it is consistent with the principle of the international law (Ibid: 127). This principle has been defined in the third clause of the Article 2 of the Geneva Convention and Article 57 of the first protocol. According to the first clause of the Article 57, "it is necessary to avoid attacking non-military forces or sacking their possessions in military actions". Also considering the second clause of the Article 57, it is necessary to warn the civilians before starting their military actions. Most of the conventions about using specific armaments has also emphasized on the importance of following the principle of precautionary (Queguiner, 2006:795).

An advanced remote/ robotic armament vehicle may have different destructive effects and it has the power to underestimate the necessary precautionary measures. According to the studies regarding the physical and sensory distances between the aircraft's operator and the unmanned combat aerial vehicle, these factors affect the form of attacks and increase the possibility of military crimes. Also, the international committee of the Red Cross is concerned about the destructive effects of these armaments (Beerli, 2010:11). According to the second clause (B) of the Article 57 of the first protocol, "All the states should consider the principle of precautionary in the process of selecting war tactics and equipment. The selected armaments are not allowed to attack non-military individuals or harm them. Also they can't destroy civilians' possessions. According to the Clause C of the mentioned article, "The military forces should warn civilians before starting their military acts or attacks". The third clause of the Article 52 of the first protocol has also emphasized on this issue. Mosques, houses, and schools that are public places, shouldn't be targeted by these armaments or use for military purposes. However, some countries don't consider these principles and attack all these public places in wars. In other words they violate the principle of precautionary actions. Even if we suppose that one person or a group of people identified as military targets, it is not legal to use these armaments because other individuals are civilians and they shouldn't be injured. As a result if military forces attack them it means that they have violated the mentioned 
principle (Stanford Clinic, 2012:114).

The principle of precaution has encountered with different challenges regarding the use of unmanned combat aerial vehicles in wars. Now the question is that how a remote. Robotic armament vehicle can analyze the precautionary actions and make appropriate decisions for the attacks? For example, is it possible for this armament to predict its destructive and harmful effects or not? Now, none of these armaments have this power. They can't make decisions about the destructive effects of attacks for civilians or follow the principles that are consistent with the all the risks and military purposes. It can be concluded that following the principle of the precautionary actions require human power of decision making (Boothby, 2012:123). Considering the results of the conference of the international committee of the Red Cross in 2014, advanced robotic/remote armament systems don't have the power of decision making. Also their compatibility power is restricted and they can't analyze different conditions like human. As a result, they are not efficient in non-predictable situations. This problem in itself increases the challenges about the inability of these systems in following the principle of precautionary actions, compatibility, and discrimination especially on dynamic and difficult conditions. Now, none of these armaments have this power and it is unlikely that they become able to follow these principles in the future. (https://www.icrc.org/eng/resources/documents/statement/2014/05-13-autonomous-weaponsstatement.htm). In 2013, Kathleen Lavand, the chief of armaments of the international committee of the Red Cross emphasized that these armaments don't have the ability to analyze, select, or fulfill the precautionary actions that play an important role in minimizing the destructive effects of military actions because it requires substantial analysis of the predictable and destructive effects of war or in other words human judgments (https://www.icrc.org/eng/resources/documents/statement/2013/09-03-autonomousweapons.htm)

\subsection{The Principles of Humanity and Dictates of Public Conscience (Martens Clause)}

The Martens clause has been defined in the Geneva Convention in 1899 and emphasized in the introduction part of the fourth convention in 1907 (Tyler, 2013:712-713). According to the second clause of the Article 1 of the first protocol, "The international law preserves the right of all the non-military individuals and combatants even when the recent protocol and other international conventions can't protect their rights or define a new principle which is consistent with the principles of the humanitarian law". Also in the introduction part of the fourth convention it has been mentioned that, "On certain conditions that no specific legal principle is defined in order to preserve human right, every soldier can make decisions about using these armaments and military actions relying on his conscience". This principled has been repeated several times in different conventions of the international humanitarian law (Meron, 2006: 16). According to this principle, the parties to the conflict should follow the principles of the international law, humanity also rely on their conscience in the process of decision making (op.cit.Tyler, 2013:713-714). The Martens clause has supported the fact that, "All the other military actions that not mentioned in this convention are not necessarily legal". This clause has analyzed different factors such as the application of specific weapons and prohibition of unnecessary destructive and harmful effects that play an important role in the process of analyzing the legitimacy of using armament systems and war tactics. This clause promotes the principle of the international law and emphasizes on the importance of it in the field of humanitarian law. In general these principles limit the freedom of different states in using the armaments that are not legal (Op.cit.Meron:28). The international humanitarian law is consistent with the principles of restriction and protection or in other words it emphasizes on the role of humanity in the international humanitarian law. This principle has limited the military actions, equipment, and tactics in order to preserve the right of wars' victims (Zamani, 2012:150). According to Martens clause, all the states are free in selecting war tactics and armaments. In this clause, conscience can be defined in two different forms: 1- The word "Conscience" refers to public opinions that affect the decisions of parties to the conflict and develop the principles of the international law. 2- It is the result of legal principles and approaches that emphasize on its role in both judicial and political fields. The hatred of a specific armament can be considered as an important factor in inhibiting different states from using it in battlefields. Also, the hatred of biological and chemical weapons affects this process. Christopher Greenwood believes that 'Martens clause is one of the factors that can put all the states under the pressure to accept the prohibition of using some of the mentioned armaments (Op.cit.Meron:23-25). This clause especially focuses on the prohibition of using unmanned combat aerial vehicles and it is consistent with the principle of the international law which in itself limits the use of these armaments (verschuren, 2012:55). In 2013, Christoph Heyns, the UN special rapporteur has written a report to the UN human rights council regarding the use of independent armaments: Martens clause can be considered as a binding and ancient rule in the international humanitarian law. Considering this principle, advanced remote/ robotic armament systems that are out of the control of human beings can threat humanity. Therefore, Martens clause prohibits the use of these armaments (Heyns, 2013:17-19). According to the statements of the experts in 
the international committee of the Red Cross, the principles of public conscience and humanity don't permit states to use robotic armament systems that cannot be controlled by human beings or make decisions about people's lives. Even when the military purpose is legal, only human beings have the power to make decisions about people's lives (https://www.icrc.org/eng/resources/documents/statement/2014/05-13-autonomousweapons-statement.htm). In 2012, the Human Rights Watch stated that Martens clause has increased concerns about the application of independent armament systems. As a result, the number of opponent approaches has increased too. Each of these approaches emphasize on the disadvantages of these armaments (Op.cit.Docherty: 35-36). Therefore, violating the principles of the international humanitarian law and threating the life of innocent people is contrary to the principles of humanity and public conscience.

\section{Conclusion}

Every state has the responsibility to analyze the legitimacy of different forms of armaments before using them in battlefield and based on the Article 36 of the first protocol. According to the interpretations of the international committee of the Red Cross, the legitimacy of unmanned combat aerial vehicles should be analyzed. It seems that this interpretation is consistent with the principle of humanitarian law. No specific convention has been formed regarding the prohibition or restriction of manufacturing or developing these armaments. According to the weapons law, an unmanned combat aerial vehicle in itself doesn't violate the principle of avoiding any form of unnecessary destructive and harmful effects and we cannot rely on its nature to consider it illegal. However, it doesn't mean that different states have this permission to use these armaments in wars. Some of the features of these unmanned combat aerial vehicles such as flying at high altitudes, inability of the sensors in gathering efficient information and discriminating military targets from civilians affect the decisions about legitimacy of these armaments. Also the distance between the aircraft's operator and military targets affect the principles of the international humanitarian law. An operator can easily identify a group of people in a specific area but it doesn't have enough power to distinguish armed individuals from civilians or injured people or combatants who decided to cease the fire. As a result, a 1-4 delay in the process of sending information from the operator to the unmanned combat aerial vehicle may have inevitable destructive effects for non-military individuals. These predictions have increased the challenges regarding the use of unmanned combat aerial vehicles. These armaments violate the principle of discrimination especially when they want to identify a military target and attack it. The principles of discrimination and compatibility have different definitions in the international humanitarian law though they complete each other. It means that if an armament system can't follow the principle of discrimination, it can violate the principle of compatibility too. As a result, it is necessary for the parties to the conflict to use armaments that are consistent with these principles. The principle of precautionary action has a significant relationship with other principles of the international humanitarian law. It can be considered as one of the main components of the principle of discrimination in the international humanitarian law. An operator should control the necessity and compatibility of military attacks in a consistent manner and postpone the attacks in order to minimize the destructive effects of using these armaments. Considering these matters, it is unlikely that unmanned combat aerial vehicles especially independent or remote ones follow the principle of the international humanitarian law. The Martens clause supports these principles. It emphasizes on the importance of prohibiting or restricting the use of unmanned combat aerial vehicles.

\section{References}

Akerson, D. (2014). To Apply Justice of Bello Proportionally to Drone Warfare. Or. Rev. Int'l L., 16, 173.

Alberstadt, R. (2014). Drones under International Law. Open Journal of Political Science, 4, 221-232. https://doi.org/10.4236/ojps.2014.44023

Anderson, K., Reisner, D., \& Waxman, M. C. (2014). Adapting the Law of Armed Conflict to Autonomous Weapon Systems.

$\begin{array}{lllll}\text { Autonomous } & \text { weapon } & \text { systems. } & \text { (n.d.). } & \text { Retrieved }\end{array}$ https://www.icrc.org/en/document/autonomous-weapon-systems-challenge-human-control-over-use-force

Autonomous weapons: ICRC addresses meeting of experts. (2014). Retrieved from https://www.icrc.org/eng/resources/documents/statement/2014/05-13-autonomous-weapons-statement.htm

Beerli, Ch. (2010). Technological Challenges for the Humanitarian Legal Framework. Retrieved from https://www.coleurope.eu/sites/default/files/uploads/page/collegium_41_0.pdf

Boothby, W. (2012). Some Legal Challenges Posed by Remote Attack. International Review of the Red Cross, 94(886), 579-595. https://doi.org/10.1017/S1816383112000719

Collina, T. Z. (2012). The Conventional Armed Forces in Europe (CFE) Treaty \& the Adapted CFE Treaty at a 
Glance. Arms' Control Association.

Dalamagkidis, K., Valavanis, K. P., \& Piegl, L. A. (2011). On Integrating Unmanned Aircraft Systems into national airspace system: issues, challenges, operational restrictions, certification, \& recommendations (Vol. 54). Springer Science \& Business Media.

Docherty, B. (2012). Losing Humanity: The Case against Killer Robots.

Evans, T. D. (2012). At War with the Robots: Autonomous Weapon Systems \& the Martens Clause. Hofstra L. Rev., 41, 697.

Fatima, K. (2015). the Use of Drones \& Private Military Companies in Modern Warfare: Effect on International Humanitarian Law. Journal of the Asiatic Society of Bangladesh (Hum.), 59(2), 367-384.

Foy, J. (2014). Autonomous Weapons' Systems: Taking the Human Out of International Humanitarian Law. Dalhousie J. Legal Studies, 23, 47.

$\begin{array}{lllll}\text { Fully autonomous } & \text { weapon } & \text { systems. } & \text { (2013). } & \text { Retrieved from }\end{array}$ https://www.icrc.org/eng/resources/documents/statement/2013/09-03-autonomous-weapons.htm

Hattan, T. (2014). Lethal Autonomous Robots: "Are They Legal Under International Human Rights \& Humanitarian Law?" Neb. L. Rev., 93, 1035.

Henckaertz, M., \& Dosoldebk. (2008). The International Humanitarian Law (translated in the department of international affairs of the judiciary bureau \& the international committee of the Red Cross). Tehran, Majd press.

Herman, O. (2013). Rise of Drones: A Study on the Legality of Drone Targeted Killings of Suspected Terrorists. Retrieved

from http://www.scriptiebank.be/sites/default/files/webform/scriptie/MasterThesisOliviaHerman.pdf

Heyns, C. (2011). Report of the Special Rapporteur on Extrajudicial, Summary or Arbitrary Executions: Addendum, Follow-up to country recommendations: Afghanistan.

Heyns, C. (2016). Extrajudicial, Summary, or Arbitrary Executions. Security Issues in the Greater Middle East, 183.

ICRC, EXPERT meeting. (2014). Autonomous Weapon: Systems Technical, Military, Legal \& Humanitarian Aspects. Retrieved from https://www.law.upenn.edu/live/files/4006-expert-meeting

Ismail Nasab, H. (2014). A Collection of the Most Important Documents of the International Law. Tehran, Jangal press.

Jens, D. (2013). The Duty to Capture: Minnesota Law Review, 97, 1268-1342.

Lachowski, Z., \& Poust, S. (2009). The Process of Controlling Ordinary Armamnets. SIPRI yearbook 2009. Retrieved from http://www.sipri.org/yearbook/2009/farsi/11

Lawand, K. (2006). Reviewing the Legality of New Weapons, Means \& Methods of Warfare. International review of the Red Cross, 88(864), 925-930. https://doi.org/10.1017/S1816383107000884

Leveringhaus, A., \& Giacca, G. (2014). Robo-Wars: The Regulation of Robotic Weapons.

Liu, H. Y. (2012). Categorization \& legality of Autonomous \& Remote Weapons Systems. International Review of the Red Cross, 94(886), 627-652. https://doi.org/10.1017/S181638311300012X

Loewen, H. (2013) UAV Export Controls. Retrieved from https://www.micropilot.com/pdf/uav-export-controls. pdf

Mark, R. V. (2012). Drone Wars: The Legal Framework for Remote Warfare. FAOA Journal of International Affairs, 15(3), 21.

McClelland, J. (2003). The Review of Weapons in Accordance with Article 36 of Additional Protocol I. Revue International de la Croix-Rouge/International Review of the Red Cross, 85(850), 397-420. https://doi.org/10.1017/S1560775500115226

McDougall, R. (2003). The Process of Controlling the Development of Missiles, the Missile Technology Control Regime \& Its Worldwide Use (translated by Hojjatzadeh). Negah journal, (41).

Meron, T. (2006). The Humanization of International Law (pp. 1-89). Leiden: Martinus Nijhoff.

Mirfakhraei, H. (2007). "The Crisis of Establishing the united States' Defensive Missile in Eastern Europe": The 
Objectives \& Consequences. the journal of politics \& law, (22).

Missile Technology Control Regime (MTCR). (n.d.). Retrieved from http://fas.org/nuke/control/mtcr

Phil, Sh. (2013). The Legality of The UK's Use of Armed Unmanned Aerial Vehicles (Drones). Retrieved from https://dronewarsuk.files.wordpress.com/2013/06/pil-peacerights-legal-opinion-re-uk-drones-3-june-2013b. pdf

Quéguiner, J. F. (2006). Precautions under the Law Governing the Conduct of Hostilities. International Review of the Red Cross, 88(864), 793-821. https://doi.org/10.1017/S1816383107000872

Quintana, E. (2008). The Ethics \& Legal Implications of Military Unmanned Vehicles. RUSI, Occasional Paper.

Radziejowska, M. (2014) Remote \& Autonomous From Drones to "Killer Robots", Polish Institute of International Affairs (PISM), Warsaw, Poland, Volume: 24, Issue: 60.

Saed, N. (2007). Analyzing the Function of the Missile Technology Control Regime \& Defensive Actions of the Islamic Republic of Iran. Defense Policy journal, (59).

Serbin, E. (2014). Lethal Autonomous Robots: A Test for the International Humanitarian Law. Security Index: A Russian Journal on International Security, 20(3-4), 57-68. https://doi.org/10.1080/19934270.2014.986367

Sharkey, N. E. (2012). The Viability of Autonomous Robot Warfare. International Review of the Red Cross, 94(886), 787-799. https://doi.org/10.1017/S1816383112000732

Taghizadeh, Z., \& Hadavandi, F. (2012). Analyzing the Legitimacy of Using Unmanned Combat Aerial Vehicles Based on the Principles of the International Law. International Studies Journal, (4).

Thomas, B. T. (2015). Autonomous Weapon Systems: The Anatomy of Autonomy \& the Legality of Lethality. Houston Journal of International Law, 37(1).

Unmanned Aerial Vehicles $\quad$ (UAVs). $\quad$ (n.d.). $\quad$ Retrieved from http://www.britannica.com/technology/military-aircraft/Unmanned-aerial-vehicles-UAVs

Verschuren, S. (n.d.). The Development of Unmanned Weapons \& the Challenges for International Law.

Vogel, R. J. (2011). Drone Warfare \& the Law of Armed Conflict. Denver Journal of International Law \& Policy, $39(1)$.

Wagner, M. (2014). Dehumanization of International Humanitarian Law: Legal, Ethical, \& Political Implications of Autonomous Weapon Systems. The. Vand.J.Transnat'l L., 47, 1371.

Weizmann, N. (2013). Remotely Piloted Aircraft \& International Law. Retrieved from https:/www.icrc.org/eng/assets/files/2013/remotely-piloted-aircraft-ihl-weizmann.pdf

Wuschka, S. (2011). The Use of Combat Drones in Current Conflicts-A Legal Issues or a Political Problem. The. Goettingen J. Int'l L., 3, 891.

Zamani, Gh., \& Piri, H. (2012). The Role of National Interest in the International Humanitarian Law. The international humanitarian law, the judiciary law journal, (79).

\section{Copyrights}

Copyright for this article is retained by the author(s), with first publication rights granted to the journal.

This is an open-access article distributed under the terms and conditions of the Creative Commons Attribution license (http://creativecommons.org/licenses/by/4.0/). 